\title{
The relationship between twitch depression and twitch fade during neuromuscular block produced by vecuronium: correlation with the release of acetylcholine
}

\author{
Shashi B Bhatt*1, Jack Kohl1, Anton Amann ${ }^{2}$ and Vladimir Nigrovic ${ }^{1}$
}

Address: ${ }^{1}$ Department of Anesthesiology, College of Medicine, University of Toledo, Toledo, OH, USA and ${ }^{2}$ Department of Anesthesiology and Critical Care Medicine, Medical University of Innsbruck, Innsbruck, Austria, and Department of Environmental Sciences, Federal Institute of Technology, Zürich, Switzerland

Email: Shashi B Bhatt* - shashi.bhatt@utoledo.edu; Jack Kohl - jack.kohl@utoledo.edu; Anton Amann - anton.amann@i-med.ac.at; Vladimir Nigrovic - vladimir.nigrovic@utoledo.edu

* Corresponding author

Published: 16 July 2007

Theoretical Biology and Medical Modelling 2007, 4:24 doi:1 0.1 I86/I 742-4682-4-24

This article is available from: http://www.tbiomed.com/content/4/I/24

(c) 2007 Bhatt et al; licensee BioMed Central Ltd.

This is an Open Access article distributed under the terms of the Creative Commons Attribution License (http://creativecommons.org/licenses/by/2.0), which permits unrestricted use, distribution, and reproduction in any medium, provided the original work is properly cited.

\begin{abstract}
Background: Train-of-four stimulation pattern following the administration of non-depolarizing neuromuscular blocking drugs reveals fade on successive contractions. Fade is caused by the release of fewer acetylcholine molecules by the fourth $\left(A_{4}\right)$ than by the first stimulus $\left(A_{1}\right)$. The current study was conducted to define the relationship between the clinically observed fade and the simulated decline in acetylcholine release $\left(A_{4} / A_{1}\right)$ that would be necessary to produce it.
\end{abstract}

Methods: The $T_{4} / T_{1}$ ratios produced by different doses of vecuronium $\left(15-80 \mu g^{\cdot} \mathrm{kg}^{-1}\right)$ were plotted as a function of the concomitant $T_{1}$. Separately in a model of neuromuscular transmission, $T_{1}, T_{4}$, and $T_{4} / T_{1}$ were estimated using simulations in the presence and in the absence of a neuromuscular blocking drug and a stepwise decrease in $A_{4}$, but constant $A_{1}$.

Results: Vecuronium induced neuromuscular block was associated with larger $T_{4} / T_{1}$ ratios (less fade) during the onset than during the offset of the block. All doses caused similar fade during offset. Simulations revealed that the smallest $T_{4} / T_{1}$ was associated with the nadir of $A_{4} / A_{1}$ and occurred at the beginning of $T_{1}$ recovery. The nadir of $A_{4} / A_{1}$ was only marginally affected by the dose of vecuronium: $15 \mu g^{\cdot} \mathrm{kg}^{-1}$ producing the minimum $A_{4} / A_{1}$ of 0.8 and $80 \mu g^{k g}{ }^{-1}$ the minimum $A_{4} / A_{1}$ of 0.7 .

Conclusion: The hysteresis in the fade between onset and offset appears to be caused by a delayed decrease of $A_{4} / A_{1}$ as compared with the decrease in $T_{1}$. Tentative estimates of the decrease in $A_{4} / A_{1}$ during fade produced by vecuronium are offered. However, the validity of these estimates is dependent on the validity of the assumptions made in simulations.

\section{Background}

Non-depolarizing neuromuscular blocking drugs cause a dose-dependent decrease in the indirectly evoked muscle contractions (twitches). Upon repetitive stimulation, the successive twitches during partial nondepolarizing block are reduced more than the first twitch. This phenomenon is known as fade. The ratio of the twitch strength produced by the fourth stimulus $\left(\mathrm{T}_{4}\right)$ compared to that pro- 
duced by the first stimulus $\left(T_{1}\right)$, i.e. $T_{4} / T_{1}$, elicited by a train-of-four (TOF) stimuli is of interest to both anesthesiologists and physiologists. Anesthesiologists use the $\mathrm{T}_{4} /$ $\mathrm{T}_{1}$ ratio as an indirect measure of the still present muscle paralysis [1-3], while physiologists study the fade to gain insight into the processes of neuromuscular transmission [4-6].

Bowman [7] and others [4,8-10] have suggested that neuromuscular blocking drugs produce twitch fade during repetitive stimulation by binding to the presynaptic cholinoceptors and inhibiting the positive auto-feedback action of acetylcholine (ACh) on its own release elicited during repetitive stimulation. This action of neuromuscular blocking drugs causes the stimuli following the first stimulus to release fewer ACh molecules.

We have conducted the following study in an attempt to relate the clinically observed twitch fade, to the decrease in ACh that could account for the fade elicited by a train of four stimuli. In the first part of the investigation, we studied twitch depression and twitch fade in human subjects following the administration of different doses of vecuronium. In the second part, we expanded our model of neuromuscular transmission[11] by considering a decrease in the release of ACh elicited by the fourth stimulus.

\section{Methods Clinical experiments}

After approval by the local IRB, 21 ASA physical status I or II, adult non-obese subjects scheduled for elective surgery consented to participate in the study. Following the i.v. administration of midazolam $1-2 \mathrm{mg}$ and fentanyl $3-5$ $\mu \mathrm{g} \cdot \mathrm{kg}^{-1}$, anesthesia was induced with propofol $2-3 \mathrm{mg}$. $\mathrm{kg}^{-1}$. Tracheal intubation was performed following the topical application of lidocaine $(4 \%, 3 \mathrm{ml})$. Anesthesia was maintained with propofol infusion $(100-150 \mu \mathrm{g} \cdot \mathrm{kg}$ ${ }^{1} \cdot \mathrm{min}^{-1}$ ) and $66 \% \mathrm{~N}_{2} \mathrm{O}$ in oxygen. Ventilation was controlled to maintain normocapnia.

The thumb of one hand was abducted (preload between $250 \mathrm{~g}$ and $300 \mathrm{~g}$ ) and connected to a force transducer (Gould FT-10, Grass Telefactor, West Warwick, RI). The signal from the force transducer was amplified, digitized at $100 \mathrm{~Hz}$, and recorded on a PC using PolyVIEW data acquisition and analysis software (version 2.5, Astro-Med, Inc., West Warwick, RI) for subsequent analysis.

Supramaximal stimuli were delivered to the ulnar nerve at the wrist via skin electrodes. Baseline stabilization was obtained by applying $1 \mathrm{~Hz}$ stimuli for 20 minutes. Following the stabilization period, the stimulation was changed to a TOF pattern, i.e. four supramaximal stimuli at $2 \mathrm{~Hz}$, and the trains repeated at $12 \mathrm{~s}$ intervals. Vecuronium was injected in doses ranging from $15 \mu \mathrm{g} \cdot \mathrm{kg}^{-1}$ to $80 \mu \mathrm{g} \cdot \mathrm{kg}^{-1}$. The doses were chosen to produce a wide range of twitch depression, including the complete ablation of $\mathrm{T}_{1}$. The recorded strengths of $\mathrm{T}_{1}$ and $\mathrm{T}_{4}$ were expressed as fractions of $\mathrm{T}_{1}$ before the administration of vecuronium. The recordings were continued until complete spontaneous recovery from the neuromuscular block. The results are reported only for those subjects in whom $\mathrm{T}_{1}$ returned to within $\pm 10 \%$ of the baseline.

\section{Simulation of $T_{1}$ and $T_{4}$ as related to the release of acetylcholine by the first and the fourth stimuli}

The strength of the twitches elicited by the first and the fourth stimuli in a TOF stimulation pattern was simulated in the model of neuromuscular transmission [11]. The model considers the stimulus-induced release of ACh into a synaptic cleft, ACh binding to two sites at a single postsynaptic receptor, and ACh hydrolysis. The number of ACh molecules released by the first stimulus was postulated to establish a constant initial concentration of ACh, $[\mathrm{A}]_{1}=7.75 \times 10^{-6} \mathrm{M}$. The model was expanded by assuming that the fourth stimulus releases either the same or a smaller number of ACh molecules, and establishes the initial concentration of ACh in the synaptic cleft denoted by $[\mathrm{A}]_{4}$. The ratio $[\mathrm{A}]_{4} /[\mathrm{A}]_{1}$ was assigned nine values from 1.0 to 0.8 in steps of 0.025 , and two additional values for $[\mathrm{A}]_{4} /[\mathrm{A}]_{1}=0.75$ and 0.70 . The concentration of the postsynaptic receptors in the synaptic cleft, $[R]$, was assumed to be $7.75 \times 10^{-5} \mathrm{M}[11]$.

Binding of ACh to two sites at a postsynaptic receptor was defined by the association rate constant $k_{\text {association }}$ identical for both sites, $k_{\text {association }}=1.35 \times 10^{8} \mathrm{M}^{-1} \cdot \mathrm{s}^{-1}$. The assigned dissociation rate constants, $k_{\text {dissociation' }}$ were different: for site $_{1} k_{\text {dissociation }}=1350 \mathrm{~s}^{-1}$, and for site $_{2} k_{\text {dissociation }}=$ $13500 \mathrm{~s}^{-1}$. The assignments define two equilibrium dissociation constants, $K_{\mathrm{A} 1}=10^{-5} \mathrm{M}$ for site ${ }_{1}$, and $K_{\mathrm{A} 2}=10^{-4} \mathrm{M}$ for site ${ }_{2}$. Affinities of ACh for the binding sites are the reciprocals of the equilibrium dissociation constants. After the release of $\mathrm{ACh}$, three complexes are formed between ACh and the receptors: ARO, ORA, and ARA. Here, the first and the third letter indicate the species occupying site $_{1}$ and site ${ }_{2}$, A is ACh, O is an empty site, and $\mathrm{R}$ is the postsynaptic receptor. The complex ARA represents the activated postsynaptic receptors. The concentrations of all three complexes increase transiently after the release of $\mathrm{ACh}$, reach a peak, and subsequently decline due to hydrolysis of free ACh. We assigned a first-order rate constant for hydrolysis of ACh $\left(k_{\text {hydrolysis }}\right)$ at $12000 \mathrm{~s}^{-}$ ${ }^{1}[11]$.

The strength of $\mathrm{T}_{1}$ or $\mathrm{T}_{4}$ was calculated based on the assumption that a muscle fiber contracts when [ARA] reaches or surpasses the threshold level of [ARA] for that fiber [11]. The strength of $\mathrm{T}_{1}$ or $\mathrm{T}_{4}$ depends on the number of contracting fibers. All those fibers with a threshold [ARA] at or below the calculated peak value of [ARA] contract. The twitches, be it $\mathrm{T}_{1}$ or $\mathrm{T}_{4}$, were calculated identi- 
cally using the calculated peak value of [ARA] after the first or the fourth stimulus:

$$
\text { Twitch }=\frac{\text { peak }[\text { ARA }]^{\gamma_{\mathrm{A}}}}{\text { peak[ARA }]^{\gamma_{\mathrm{A}}}+[\text { ARA50 }]^{\gamma_{\mathrm{A}}}}
$$

where $\gamma_{A}$ characterizes the distribution of the threshold [ARA] among the fibers of the muscle and [ARA50] is the median of all threshold [ARA] [11]. We used the previously defined values: $\gamma_{\mathrm{A}}=4.732$ and [ARA50] $=9.524 \times$ $10^{-9} \mathrm{M}[11]$.

The hypothetical muscle relaxant D competes with ACh for binding to the same two sites at a postsynaptic receptor. The assigned constants for the interaction were: $k_{\text {associ- }}$ ationD identical for both binding sites, $k_{\text {associationD }}=4.0 \times$ $10^{8} \mathrm{M}^{-1} \mathrm{~s}^{-1}$, and the equilibrium dissociation constants $K_{\mathrm{D} 1}$ $=10^{-7}$ for site ${ }_{1}$ and $K_{\mathrm{D} 2}=10^{-6} \mathrm{M}$ for site $_{2}$. The dissociation rate constants were calculated from $k_{\text {dissociationD }}=K_{\mathrm{D}} \cdot k_{\text {asso- }}$ ciationD. Similar to ACh, the muscle relaxant $\mathrm{D}$ produces three types of complexes by itself, e.g. DRO, ORD and DRD, and two additional mixed complexes with ACh, ARD and DRA. The molar concentrations of $D$ in the synaptic cleft are labeled $[D]_{\text {synaptic cleft }}$. Higher $[D]_{\text {synaptic cleft }}$ leads to a larger fraction of the postsynaptic receptors occupied by D. In the calculations, we used 100 logarithmically equidistant values for a 10 -fold increase in $[D]_{\text {syn- }}$ aptic cleft to produce $T_{1}$ declining from its maximal value to 0.05 . This was achieved by increasing $[D]$ from $1 \cdot 10^{-8}$ to $5 \cdot 10^{6} \mathrm{M}$. We assumed that the decrease in $\mathrm{T}_{1}$ is produced exclusively by increased [D] and, hence, an increased occupancy of the postsynaptic receptors. On the other hand, the decrease in $T_{4}$ is caused by a combination of increased postsynaptic receptor occupancy and the diminished release of ACh elicited by the fourth stimulus. Neuromuscular block (NMB) was defined as the difference in strength of $\mathrm{T}_{1}$ in the absence and the presence of a muscle relaxant.

The calculations were performed using the program MATHEMATICA (version 5.2) from Wolfram Research, Inc., Champaign, IL.

\section{Results}

Although 21 subjects were studied, the first twitch returned to within $\pm 10 \%$ of the baseline in only 15 subjects and only the data from these subjects are presented. Since our measurement technique did not allow us to measure twitch tension with precision once $\mathrm{T}_{1}$ decreased to below $10 \%$ of its baseline value, we have not included in our analysis any data, be it for $T_{1}$ or $T_{4} / T_{1}$ ratios, for $T_{1}$ $<0.1$.

In all subjects studied, the peak depression of $\mathrm{T}_{4}$ lagged behind the peak depression of $\mathrm{T}_{1}$, and the minimum $\mathrm{T}_{4}$ was always lower than the minimum $\mathrm{T}_{1}$. This is illustrated for two subjects who received vecuronium doses of 15 $\mu \mathrm{g} \cdot \mathrm{kg}^{-1}$ or $35 \mu \mathrm{g} \cdot \mathrm{kg}^{-1}$, respectively (upper panel in Figure 1 ). The plot of $T_{4} / T_{1}$ as a function of $T_{1}$ for the same two subjects reveals that, for any given value of $T_{1}$, the $T_{4} / T_{1}$ ratio is higher during the onset than during the offset of NMB (lower panel in Figure 1).

The $T_{4} / T_{1}$ ratios as a function of $T_{1}$ for various doses of vecuronium during the onset of $\mathrm{NMB}$ are presented in the upper panel of Figure 2. To simplify the presentation, only one representative subject is presented for each dose. The results indicate that, at any level of $\mathrm{T}_{1}$, the $\mathrm{T}_{4} / \mathrm{T}_{1}$ ratios are higher, i.e. the twitch fade is less pronounced, with larger doses of vecuronium. Thus, at $\mathrm{T}_{1}=0.5$, a vecuronium dose of $20 \mu \mathrm{g} \cdot \mathrm{kg}^{-1}$ produced $\mathrm{T}_{4} / \mathrm{T}_{1}=0.4$. However, at the same $\mathrm{T}_{1}, \mathrm{~T}_{4} / \mathrm{T}_{1}$ was 0.78 in the subject who received the dose of $80 \mu \mathrm{g} \cdot \mathrm{kg}^{-1}$.
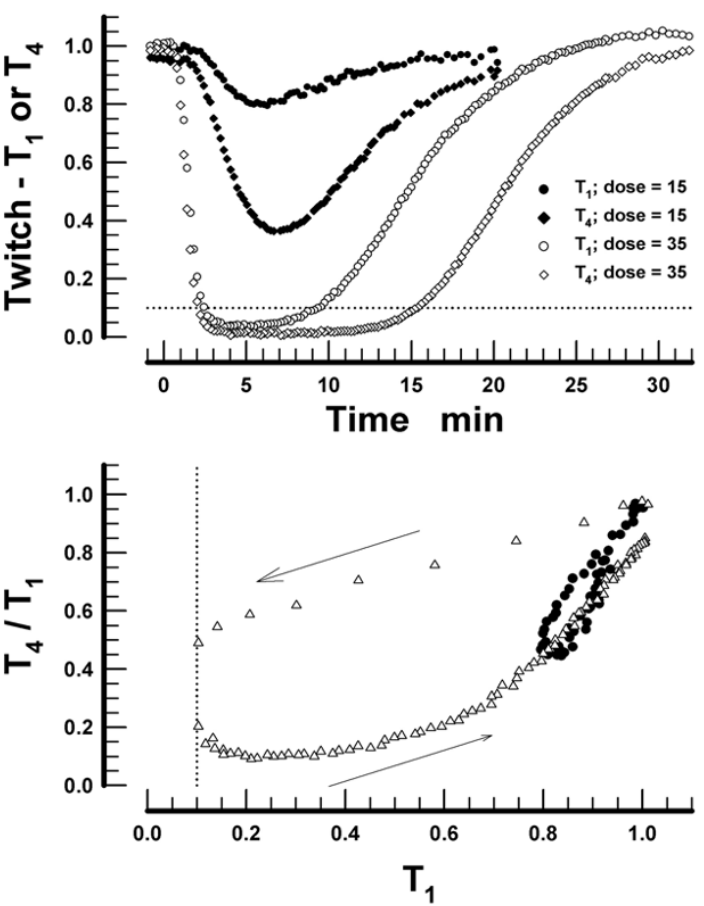

Figure I

Time-course of the first $\left(T_{1}\right)$ and the fourth twitch $\left(T_{4}\right)$ in two subjects following the injection of vecuronium. The dose of vecuronium was $15 \mu \mathrm{g} \cdot \mathrm{kg}^{-1}$ in one subject (filled symbols) and $35 \mu \mathrm{g} \cdot \mathrm{kg}^{-1}$ in the second subject (open symbols, upper panel). The dotted line parallel with the Time axis indicates twitch $=0.1$. The lower panel presents the $T_{4} / T_{1}$ ratios as a function of $T_{1}$ for the same two subjects. The loops commence at $T_{1}=1.0$ and $T_{4} / T_{1}=1.0$ and then follow the direction indicated by arrows. The dotted line parallel with the $T_{4} /$ $T_{1}$ axis indicates $T_{1}=0.1$. 
When compared at identical values of $\mathrm{T}_{1}$, the $\mathrm{T}_{4} / \mathrm{T}_{1}$ ratios during the offset of NMB (lower panel in Figure 2) were lower than those observed during the onset. The ratios were similar among the different doses of vecuronium during the offset. Therefore, we have summarized the data for $\mathrm{T}_{4} / \mathrm{T}_{1}$ during the offset of $\mathrm{NMB}$ at $\mathrm{T}_{1}=0.25,0.5,0.75$, and 0.9, and present the mean \pm SD in Figure 2.

The simulations produced 11 curves, one for each $[\mathrm{A}]_{4} /$ $[A]_{1}$ value, relating $T_{4} / T_{1}$ to $T_{1}$ (Figure 3 ). The curves indicate the inter-relationship between $\mathrm{T}_{1}, \mathrm{~T}_{4} / \mathrm{T}_{1}$, and $[\mathrm{A}]_{4} /$ $[\mathrm{A}]_{1}$. The relationship may be summarized as follows: $(i)$
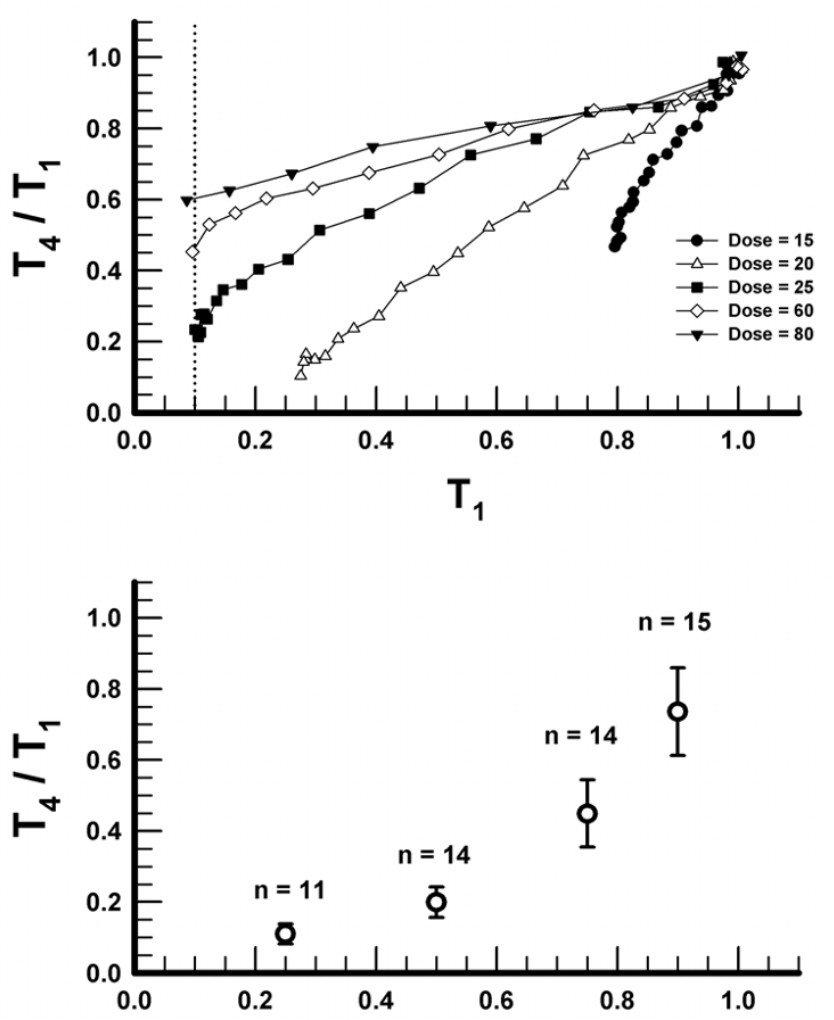

Figure 2

Upper panel: The ratios of the fourth to the first twitch $\left(\mathrm{T}_{4} /\right.$ $T_{1}$ ) as a function of the first twitch $\left(T_{1}\right)$ for various doses $\left(\mu \mathrm{g} \cdot \mathrm{kg}^{-1}\right)$ of vecuronium (individual subjects) during the onset of neuromuscular block. At the moment of vecuronium injection, $T_{1}=1.0$ and $T_{4} / T_{1}=1.0$. Lower panel: $T_{4} / T_{1}$ ratio (mean \pm SD) as a function of $T_{1}\left(\right.$ at $T_{1}=0.25,0.5,0.75$, and 0.9 ) for all doses of vecuronium during the offset of neuromuscular block. The number of subjects is indicated by $n$. The temporal sequence of observations starts at the lowest value of $T_{1}$ and progresses toward higher values of $T_{1}$. The label for the $\mathrm{X}$-axis is identical to the label of the $\mathrm{X}$-axis in the upper panel. at a constant $T_{1}$, the $T_{4} / T_{1}$ ratio is higher for higher $[A]_{4} /$ $[\mathrm{A}]_{1}$; $\left(\right.$ ii) at a constant $[\mathrm{A}]_{4} /[\mathrm{A}]_{1}$, the $\mathrm{T}_{4} / \mathrm{T}_{1}$ ratio is lower for lower values of $\mathrm{T}_{1}$; (iii) a given $\mathrm{T}_{4} / \mathrm{T}_{1}$ may be associated with many combinations of $[\mathrm{A}]_{4} /[\mathrm{A}]_{1}$ and $\mathrm{T}_{1}$; and $(\mathrm{iv}) \mathrm{a}$ pair of $\mathrm{T}_{4} / \mathrm{T}_{1}-\mathrm{T}_{1}$ values is associated with a unique value of $[\mathrm{A}]_{4} /[\mathrm{A}]_{1}$. If the fourth stimulus releases the same number of ACh molecules as does the first, i.e. if $[\mathrm{A}]_{4} /[\mathrm{A}]_{1}=1$, then $T_{4}$ remains equal to $T_{1}$, i.e. $T_{4} / T_{1}=1$, for any value of $T_{1}$ (Figure 3).
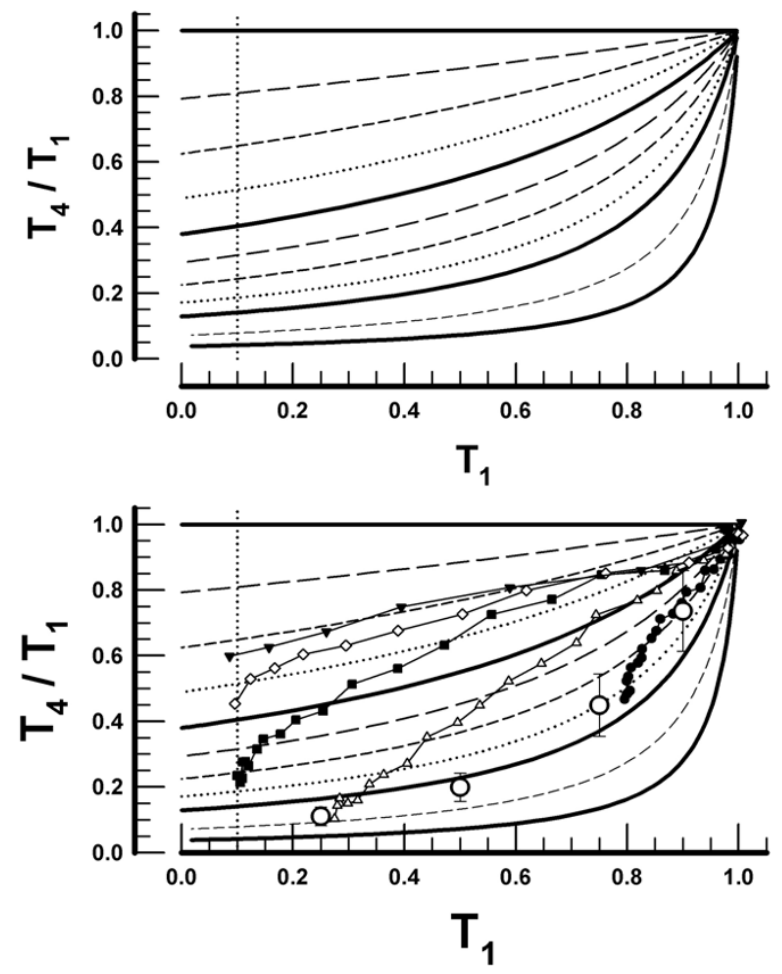

Figure 3

Upper panel: The ratios of the fourth to the first twitch $\left(\mathrm{T}_{4} /\right.$ $T_{1}$ ) as a function of $T_{1}$. The I I curves were obtained in simulations assuming a constant amount of acetylcholine released by the first stimulus $\left([A]_{l}\right)$ and either the same or smaller amounts released by the fourth stimulus $\left([\mathrm{A}]_{4}\right)$. The ratios of the initial concentrations of acetylcholine released by the fourth and the first stimulus are denoted by $[A]_{4} /[A]_{1}$. The continuous bold curves indicate, in descending order, $[\mathrm{A}]_{4} /$ $[\mathrm{A}]$, ratios of $1.0,0.9,0.8$, and 0.7 , respectively. For the intermediate values of $[\mathrm{A}]_{4} /[\mathrm{A}]_{\text {, }}$ see Methods. Lower panel: The observed $T_{4} / T_{1}-T_{1}$ data pairs during the onset of NMB and the mean values during the offset are inserted into the grid of the $T_{4} / T_{1}$ versus $T_{1}$ curves presented in the upper panel. The observed data are those presented in Figure 2. 
$\mathrm{T}_{4} / \mathrm{T}_{1}-\mathrm{T}_{1}$ data pairs observed during the onset of NMB produced by different doses of vecuronium, as well as the mean values of $T_{4} / T_{1}-T_{1}$ observed in all patients during the offset of NMB (Figure 2), were superimposed on the grid relating $\mathrm{T}_{4} / \mathrm{T}_{1}$ ratios to $\mathrm{T}_{1}$ at different levels of $[\mathrm{A}]_{4} /[\mathrm{A}]_{1}$ (lower panel in Figure 3). The superimposition helps to clarify the relationship between the clinically observed data pairs and the simulated $[\mathrm{A}]_{4} /[\mathrm{A}]_{1}$ ratios.

The maximal decrease in $[\mathrm{A}]_{4} /[\mathrm{A}]_{1}$ appears to be influenced only minimally by the dose of vecuronium. For example, the smallest dose $\left(15 \mu \mathrm{g} \cdot \mathrm{kg}^{-1}\right)$ decreased $T_{1}$ to 0.8 and $[\mathrm{A}]_{4} /[\mathrm{A}]_{1}$ to 0.82 . The largest dose $\left(80 \mu \mathrm{g} \cdot \mathrm{kg}^{-1}\right)$ produced a complete ablation of $\mathrm{T}_{1}$ and yet decreased $[\mathrm{A}]_{4} /[\mathrm{A}]_{1}$ to only 0.7 .

The relationship between the observed $T_{4} / T_{1}-T_{1}$ data pairs and the simulated $T_{4} / T_{1}$ versus $T_{1}$ curves as a function of the $[\mathrm{A}]_{4} /[\mathrm{A}]_{1}$ ratios was examined in more detail in a single subject. The dose of vecuronium in this subject was 25 $\mu \mathrm{g} \cdot \mathrm{kg}^{-1}$ and the complete observed time-course for $T_{4} / \mathrm{T}_{1}$ versus $T_{1}$ is presented (Figure 4). The results indicate that the $\mathrm{T}_{4} / \mathrm{T}_{1}$ ratios correspond to different $[\mathrm{A}]_{4} /[\mathrm{A}]_{1}$ during the onset and offset of NMB. Interpolation of the observed $\mathrm{T}_{4} / \mathrm{T}_{1}-\mathrm{T}_{1}$ data pairs between the simulated $[\mathrm{A}]_{4} /$ $[\mathrm{A}]_{1}$ curves permitted us to plot the approximate $[\mathrm{A}]_{4} /[\mathrm{A}]_{1}$ ratios as a function of time after the injection of vecuronium in this subject (lower panel in Figure 4). The results reveal that, during the onset of $\mathrm{NMB}$, the decrease in $[\mathrm{A}]_{4} /$ $[A]_{1}$ lags behind the decrease in $T_{1}$. The peak depression of $[\mathrm{A}]_{4} /[\mathrm{A}]_{1}$ occurred approximately ten min after the injection of vecuronium, while the peak depression of $\mathrm{T}_{1}$ occurred after $4.5 \mathrm{~min}$.

\section{Discussion}

Our finding that vecuronium produces less fade for any given twitch depression during the onset compared to the offset of NMB (Figure 2) is consistent with the findings reported by other investigators [12-16]. We have also found that, during the onset and at similar $\mathrm{T}_{1}$, larger doses of vecuronium produce less fade than smaller doses (Figure 2). This finding is also consistent with the results from other investigations $[14,15]$. During the offset of $\mathrm{NMB}$, the pooled $T_{4} / T_{1}-T_{1}$ data pairs from all subjects (Figure 2 ) are similar to those reported by other investigators using vecuronium as well as other neuromuscular blocking drugs [12-16].

The primary purpose of the present study was to correlate twitch fade, as observed in the current study and by the other investigators, with the decrease in ACh release that would be necessary to produce the fade. The simulations are based on the postulate by Bowman [7] that twitch fade is due to the decreased amount of ACh released by the fourth stimulus as compared to that released by the first
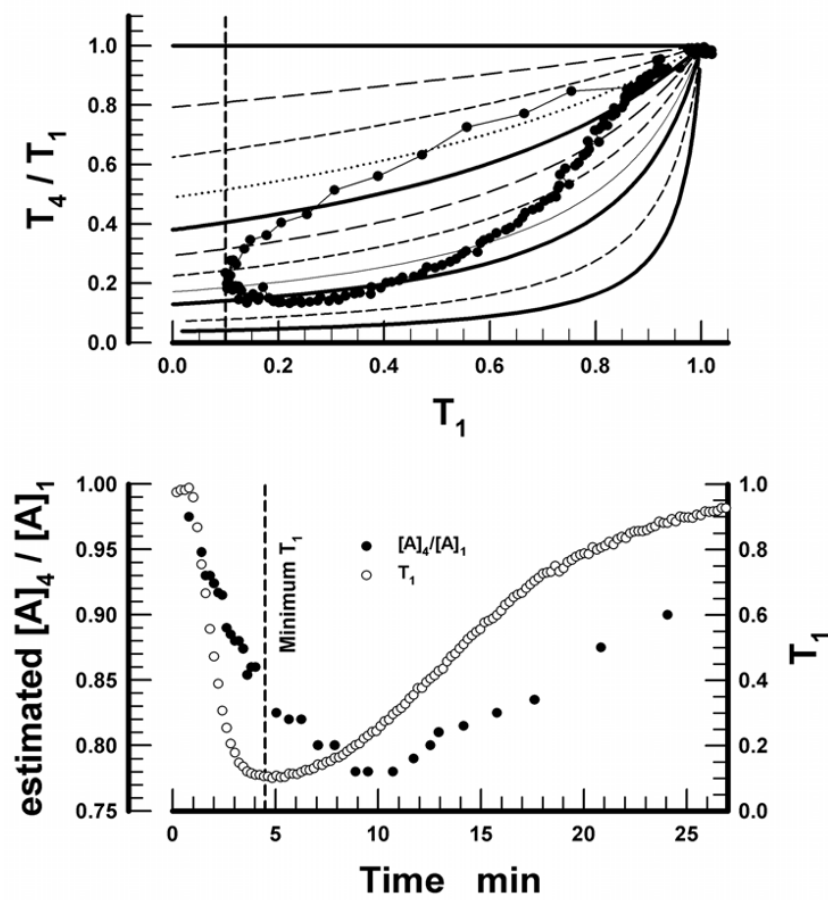

\section{Figure 4}

Upper panel: The complete set of the ratios of the fourth $\left(T_{4}\right)$ to the first twitch $\left(T_{1}\right)$ as a function of the concomitant $T_{1}$ observed in a single subject. The dose of vecuronium was 25 $\mu g \cdot \mathrm{kg}^{-1}$. The grid of the II curves is that presented in Figure 3 . The dashed line parallel with the $Y$-axis indicates the minimal $T_{1}$. Lower panel: The observed values of $T_{4} / T_{1}$ were inter-

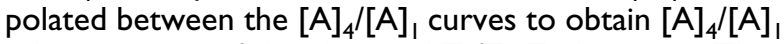
values at times of the observed $T_{4} / T_{1}-T_{1}$ data pairs. The estimated $[\mathrm{A}]_{4} /[\mathrm{A}]_{1}$, values are plotted as a function of time elapsed from the injection of vecuronium. The time-course of $T_{1}$ depression in the same subject is also plotted (right $Y$ axis, filled circles). The dashed line parallel with the $Y$-axis indicates the time of the minimal $T_{1}$.

stimulus. The correlation between the clinically observed fade and the simulated decrease in $[\mathrm{A}]_{4} /[\mathrm{A}]_{1}$ allowed us to suggest tentative estimates for the vecuronium-induced decrease of ACh release elicited by the fourth stimulus during the TOF pattern of stimulation.

We have previously investigated in simulations twitch fade caused by nondepolarizing muscle relaxants [17]. However, in that report we were interested in the properties of the muscle relaxants in relation to their interaction with the presynaptic receptors (the affinities and the rates of interaction). In the current study, our focus is on the estimate of the magnitude of the $[\mathrm{A}]_{4} /[\mathrm{A}]_{1}$ ratio necessary to explain the fade. 
The simulated result that no fade is present if the amount of ACh released by the fourth stimulus remains identical to that released by the first stimulus, i.e. if $[\mathrm{A}]_{4}=[\mathrm{A}]_{1}$ (Figure 3 ), contradicts the suggestion that, even in the absence of neuromuscular blocking drugs, a spontaneous fall-off of the ACh quantal content occurs at $2 \mathrm{~Hz}$ stimulation frequency [18]. If there were a spontaneous fall-off in ACh quantal content upon repetitive stimulation, then in the presence of a drug that binds exclusively to the postsynaptic receptors, e.g. $\alpha$-bungarotoxin or erabutoxin, the spontaneous fall-off in ACh release would, of necessity, lead to fade. However, it has been demonstrated repeatedly that these drugs produce a profound decrease in twitch height without producing fade $[5,6,19]$. Thus, the results of our simulations accord with, and support the notion of, no decline in ACh quantal content during the TOF pattern of stimulation in the absence of nondepolarizing neuromuscular blocking drugs $[9,20,21]$.

The results from our simulations suggest that fade, i.e. $\mathrm{T}_{4}$ $<\mathrm{T}_{1}$, depends on both $\mathrm{T}_{1}$ and $[\mathrm{A}]_{4} /[\mathrm{A}]_{1}$ (Figure 3 ). Signal transmission across the neuromuscular junction results from a bimolecular reaction, i.e. from ACh binding to the postsynaptic receptors. A minor decrease in one of the partners, be it of ACh or the postsynaptic receptors, to its threshold concentration is not accompanied by failure of the muscle fibers to contract. This phenomenon is known as the safety factor [22]. Our simulations suggest that, with one partner at its threshold concentration, a concomitant decrease in the concentration of the other partner decreases the safety factor below its critical values in some muscle fibers. Failure of these fibers to contract leads to a decrease in twitch strength and, if the twitch is $\mathrm{T}_{4}$, a lower $\mathrm{T}_{4} / \mathrm{T}_{1}$.

All the $\mathrm{T}_{4} / \mathrm{T}_{1}-\mathrm{T}_{1}$ data pairs observed in our study and those reported by other investigators may be interpreted on the basis of the simulated $\mathrm{T}_{4} / \mathrm{T}_{1}$ versus $\mathrm{T}_{1}$ relationship and assuming different $[\mathrm{A}]_{4} /[\mathrm{A}]_{1}$ ratios. The observed $\mathrm{T}_{4} / \mathrm{T}_{1}$ ratios correspond to $[\mathrm{A}]_{4} /[\mathrm{A}]_{1}$ varying from 1.0 to 0.7 . There appears to be a ceiling effect for the maximal decrease in $[\mathrm{A}]_{4} /[\mathrm{A}]_{1}$. Even the largest doses of vecuronium did not lead to $[\mathrm{A}]_{4} /[\mathrm{A}]_{1}<0.7$.

Whereas the lower $[\mathrm{A}]_{4} /[\mathrm{A}]_{1}$ ratios explain twitch fade, the lower ratios by themselves are insufficient to explain that: (i) the minimal value of $\mathrm{T}_{4}$ is attained later than the minimal value of $\mathrm{T}_{1}$ (Figure 1); (ii) twitch fade is not as extensive during the onset as during the offset of NMB (Figure 2 ); and (iii) during the onset, larger doses of vecuronium produce less fade at a given $\mathrm{T}_{1}$ than the smaller doses (Figure 2). These findings, confirming the previous findings of other investigators, are best explained by invoking a slow association of the nondepolarizing neuromuscular blocking drug with the presynaptic receptors and, hence, a slow development of the decrease in $[\mathrm{A}]_{4} /[\mathrm{A}]_{1}[8,14]$. The slower development of the decrease in $[\mathrm{A}]_{4} /[\mathrm{A}]_{1}$ relative to the development of $\mathrm{T}_{1}$ depression (Figure 4 ) also explains the phenomenon that larger doses of neuromuscular blocking drugs produce less fade (during the onset of $\mathrm{NMB}$ ) as compared with smaller doses. The reason is that the neuromuscular block develops faster with larger doses of a muscle relaxant. Thus, $\mathrm{T}_{1}=0.05$ is reached sooner following the doses $2 \cdot$ ED95 or 3 - ED95 than following 1 - ED95 of the same muscle relaxant. The fast development of the decrease of $\mathrm{T}_{1}$ does not allow sufficient time for $[\mathrm{A}]_{4} /[\mathrm{A}]_{1}$ to decrease ( $c f$. lower panel in Figure 4 ) and, as a consequence, the $\mathrm{T}_{4} / \mathrm{T}_{1}$ ratio is higher during the onset of the neuromuscular block following the larger doses of a muscle relaxant.

The correlation of the clinically observed time course of twitch fade to the simulated time course in the decrease in $[\mathrm{A}]_{4} /[\mathrm{A}]_{1}$ as well as the findings that the decrease in $[\mathrm{A}]_{4} /$ $[\mathrm{A}]_{1}$ develops slowly do not reveal the processes leading to the decrease in $[\mathrm{A}]_{4} /[\mathrm{A}]_{1}$.

\section{Conclusion}

The postulates that $(i)$ the fourth stimulus releases fewer ACh molecules than the first, and (ii) the decrease in $[\mathrm{A}]_{4} /$ $[\mathrm{A}]_{1}$ develops slower than the decrease in $\mathrm{T}_{1}$, adequately explain the $\mathrm{T}_{4} / \mathrm{T}_{1}$-versus- $\mathrm{T}_{1}$ relationship observed with vecuronium. The doses of vecuronium used in this study decrease the amount of ACh released by the fourth stimulus up to about $70 \%$ of the amount released by the first stimulus. However, the validity of these estimates is dependent on the validity of the assumptions made in simulations.

\section{Competing interests}

The author(s) declare that they have no competing interests.

\section{Authors' contributions}

SBB conceived the study, designed the clinical experiments, carried them out, performed data analysis, conceived the theoretical analysis and drafted the manuscript.

JK performed the clinical experiments and contributed in drafting the manuscript.

AA performed the calculations for the theoretical analysis part of the study and contributed to formulating the theoretical analysis and in drafting and revising the manuscript.

$\mathrm{VN}$ assisted in designing the experiments and in data analysis, assisted in calculations for the theoretical analysis, and contributed in drafting and revising the manuscript. 
All authors read and approved the final manuscript.

\section{Acknowledgements}

AA greatly appreciates the support by the Bernhard-Lang Research Association. The study was supported by the funds of the Department of Anesthesiology, College of Medicine, University of Toledo.

\section{References}

I. Ali HH, Savarese JJ, Lebowitz PW, Ramsey FM: Twitch, tetanus and train-of-four as indices of recovery from nondepolarizing neuromuscular blockade. Anesthesiology I 981, 54(4):294-297.

2. Ali HH, Utting JE, Gray C: Stimulus frequency in the detection of neuromuscular block in humans. Br J Anaesth 1970, 42(II):967-978.

3. Kopman AF, Yee PS, Neuman GG: Relationship of the train-offour fade ratio to clinical signs and symptoms of residual paralysis in awake volunteers. Anesthesiology 1997, 86(4):765-77I.

4. Bowman WC, Marshall IG, Gibb AJ, Harborne AJ: Feedback control of transmitter release at the neuromuscular junction. Trends Pharmacol Sci 1988, 9(1):16-20.

5. Gibb AJ, Marshall IG: Nicotinic antagonists produce differing amounts of tetanic fade in the isolated diaphragm of the rat. $\mathrm{BrJ}$ Pharmacol 1986, 89(3):619-624.

6. Hong SJ, Chang CC: Run-down of neuromuscular transmission during repetitive nerve activity by nicotinic antagonists is not due to desensitization of the postsynaptic receptor. $\mathrm{Br} J$ Pharmacol |99I, 102(4):8I7-822.

7. Bowman WC: Prejunctional and postjunctional cholinoceptors at the neuromuscular junction. Anesth Analg 1980, 59( I 2):935-943.

8. Gibb AJ, Marshall IG: Pre-and post-junctional effects of tubocurarine and other nicotinic antagonists during repetitive stimulation in the rat. J Physiol 1984, 35 I:275-297.

9. Glavinovic MI: Presynaptic action of curare. J Physiol 1979, 290(2):499-506

10. Magleby KL, Pallotta BS, Terrar DA: The effect of (+)-tubocurarine on neuromuscular transmission during repetitive stimulation in the rat, mouse, and frog. J Physiol |98I, 3 I 2:97-I I3.

II. Nigrovic V, Amann A: Competition between acetylcholine and a nondepolarizing muscle relaxant for binding to the postsynaptic receptors at the motor end plate: simulation of twitch strength and neuromuscular block. J Pharmacokinet Pharmacodyn 2003, 30(I):23-5I.

12. Gibson FM, Mirakhur RK, Clarke RS, Brady MM: Quantification of train-of-four responses during recovery of block from nondepolarising muscle relaxants. Acta Anaesthesiol Scand 1987, 3I(7):655-657.

13. Graham GG, Morris R, Pybus DA, Torda TA, Woodey R: Relationship of train-of-four ratio to twitch depression during pancuronium-induced neuromuscular blockade. Anesthesiology 1986, 65(6):579-583.

14. Pearce AC, Casson WR, Jones RM: Factors affecting train-of-four fade. Br J Anaesth 1985, 57(6):602-606.

15. Power SJ, Jones RM: Relationship between single twitch depression and train-of-four fade: influence of relaxant dose during onset and spontaneous offset of neuromuscular blockade. Anesth Analg 1987, 66(7):633-636.

16. Power SJ, Pearce AC, Jones RM: Fade profiles during spontaneous offset of neuromuscular blockade: vecuronium and gallamine compared. BrJ Anaesth 1988, 60(5):486-490.

17. Bhatt SB, Amann A, Nigrovic V: Modeling of twitch fade based on slow interaction of nondepolarizing muscle relaxants with the presynaptic receptors. J Pharmacokinet Pharmacodyn 2006, 33(4):46I-483.

18. Kamenskaya MA, Elmqvist D, Thesleff S: Guanidine and neuromuscular transmission. II. Effect on transmitter release in response to repetitive nerve stimulation. Arch Neurol 1975, 32(8):5I0-5I8.

19. Chang CC, Lee CY: Isolation of Neurotoxins from the Venom of Bungarus Multicinctus and Their Modes of Neuromuscular Blocking Action. Arch Int Pharmacodyn Ther 1963, 144:24I-257.

20. Galindo A: Prejunctional effect of curare: its relative importance. J Neurophysiol I 971, 34(2):289-30I.
21. Hubbard Jl, Wilson DF: Neuromuscular transmission in a mammalian preparation in the absence of blocking drugs and the effect of D-tubocurarine. J Physiol 1973, 228(2):307-325.

22. Wood SJ, Slater CR: Safety factor at the neuromuscular junction. Prog Neurobiol 200I, 64(4):393-429.
Publish with Biomed Central and every scientist can read your work free of charge

"BioMed Central will be the most significant development for disseminating the results of biomedical research in our lifetime. "

Sir Paul Nurse, Cancer Research UK

Your research papers will be:

- available free of charge to the entire biomedical community

- peer reviewed and published immediately upon acceptance

- cited in PubMed and archived on PubMed Central

- yours - you keep the copyright

Submit your manuscript here:

http://www.biomedcentral.com/info/publishing_adv.asp
BioMedcentral 